\title{
PD-1 silencing impairs the anti-tumor function of chimeric antigen receptor modified $T$ cells by inhibiting proliferation activity
}

Jianshu Wei, Can Luo, Yao Wang, Yelei Guo, Hanren Dai, Chuan Tong, Dongdong Ti, Zhiqiang Wu* and Weidong Han ${ }^{*}$

\begin{abstract}
Background: Blocking programmed death-1 (PD-1) is considered to be a promising strategy to improve T cell function, and this is being explored in many ongoing clinical trials. In fact, our knowledge about PD-1 is primarily based on the results of short-term experiments or observations, but how long-lasting PD-1 blockade can affect T cell function remains unclear.
\end{abstract}

Methods: We planned to use shRNA-based gene knockdown technology to mimic long-lasting PD-1 blockade. We constructed PD-1 steadily blocked chimeric antigen receptor modified T (CAR-T) cells, and with these cells we can clearly study the effects of PD-1 knockdown on T cell function. The anti-tumor function, proliferation ability and differentiation status of PD-1 silenced CAR-T cells were studied by in vitro and animal experiments.

Results: According to short-term in vitro results, it was reconfirmed that the resistance to programmed death-ligand 1 (PD-L1)-mediated immunosuppression could be enhanced by PD-1 blockade. However, better anti-tumor function was not presented by PD-1 blocked CAR-T cells in vitro or in vivo experiments. It was found that PD-1 knockdownmight impair the anti-tumor potential of CAR-T cells because it inhibited T cells' proliferation activity. In addition, we observed that PD-1 blockade would accelerate T cells' early differentiation and prevent effector T cells from differentiating into effect memory $T$ cells, and this might be the reason for the limited proliferation of PD-1 silenced CAR-T cells.

Conclusion: These results suggest that PD-1 might play an important role in maintaining the proper proliferation and differentiation of T cells, and PD-1 silencing would impair T cells' anti-tumor function by inhibiting their proliferation activity.

Keywords: PD-1 blockade, Chimeric antigen receptor modified T cells, T cell proliferation, T cell differentiation, Persistence

\section{Background}

Chimeric antigen receptor modified $\mathrm{T}$ (CAR-T) cells exhibit potent antitumor activity against hematological malignancies [1-4]. However, the translation of this success to solid tumors is still gloomy [5]. In the treatment of solid tumors, CAR-T therapy is faced with enormous difficulties, such as the immunosuppressive milieu [6,7]. In the establishment of the suppressive milieu, programmed death-1

\footnotetext{
*Correspondence: wuzhiqiang1006@163.com; hanwdrsw69@yahoo.com Department of Bio-therapeutic, Department of Molecular \& Immunology, Chinese PLA General Hospital, No. 28 Fuxing Road, Beijing 100853, China
}

(PD-1)/ programmed death-ligand 1 (PD-L1) axis is thought to play a key role $[6,8,9]$.

As an inhibitory receptor, PD-1 inhibits T cells activity by engaging with its ligands $[10,11]$. It has been widely confirmed that PD-1 blocking antibodies could help cytotoxic T lymphocytes (CTL) resist immune suppression and enhance anti-tumor functions [12-14]. And PD-1 antibodies were also reportedly able to rescue CAR-T cells from exhaustion and senescence $[15,16]$. In addition to antibodies, intrinsic PD-1 blocking by genetic modification was also proved to be effective $[17,18]$. 
Therefore, PD-1 blockade is considered to be a promising method to improve CAR-T cell function and is explored in many ongoing clinical trials.

Although this concept has solid theoretical foundation, so far few clinical outcomes clearly prove its authenticity. This dilemma inspired us to re-cognize PD-1 blockade.

In fact, the conclusion that PD-1 blockade can improve $\mathrm{T}$ cell function is mostly based on the results of short-term experiments or observations; however, the PD-1 blocking in clinical practice is usually long-lasting. This means that there is a cognitive gap between our knowledge and clinical practice, and the missing link is that we still don't know how long-lasting PD-1 blockade will affect $\mathrm{T}$ cell function.

Actually, some studies have suggested that long-lasting PD-1 blockade might induce negative feedback regulations. It has been reported that persistently blocking PD-1 (both with antibodies and with genetic modification) would up-regulate $\mathrm{T}$ cell immunoglobulin and mucin-domain containing-3 (TIM-3) and lymphocyte activation gene-3 (LAG-3) [19, 20], which forms an important mechanism to resist PD-1 blockade. In a fraction of patients, a novel pattern of hyperprogressive disease (HPD) induced by anti-PD-1 treatment was observed [21, 22]. It has also been reported that PD-1 knockout would promote exhaustion of CD8-positive T cells, and PD-1 was believed to play an important role in preventing $\mathrm{T}$ cells from overstimulation and senescence [23]. Although these studies demonstrated the possibility of the negative regulation, the effects of long-lasting PD-1 blockade on T cell functions have not been systematically evaluated, which we think is very necessary.

To this end, we constructed dual-promoter lentivirus vectors which allowed us to simultaneously express the PD-1 targeting short hairpin RNA (shRNA) and CAR molecule (ZsGreen followed). With this approach, we could clearly analyze every single CAR-T cell, whose PD1 is persistently blocked. We observed that persistent PD-1 silencing would significantly impair the anti-tumor potential of CAR-T cells, especially in long-term tumor killing or at lower effector cell to target cell (E:T) ratios. The proliferation activities, both cytokines dependent and CAR-mediated activation dependent, were found to be attenuated dramatically by PD-1 knockdown, which we believed was the main cause of CAR-T cells' impaired anti-tumor potential. In addition, it was suggested that the early-differentiation of CAR-T cells was accelerated by PD-1 knockdown, which is generally considered to be detrimental to $\mathrm{T}$ cell proliferation and persistence.

These findings illustrate that PD-1 signaling might not always be unfavorable for T cell functions. Moreover, it is essential for preventing over-rapid differentiation and maintaining normal proliferative activity. This work would help us understand the long-lasting PD-1 blockade more comprehensively, and it might have important implications for the clinical application of PD-1 blockade therapy.

\section{Methods \\ Dual-promoter lentivirus vector construction and viral production}

The dual-promoter lentivirus vector, pLVX-ShRNAIRES-ZsGreen from Biowit Biotech, was used as the basal framework for construction. We inserted the CAR sequences into the downstream of EF1a promoter and replaced the IRES sequence with the T2A sequence. Six different PD-1 targeting shRNA sequences were inserted into the downstream of U6 promoter respectively. A widely used scramble shRNA sequence was constructed into the vector in the same manner as control. Its sequence is as follows:

\section{Sense: 5' -GATCCCGCGCGATAGCGCTAATAATT TCTCGAGAAATTATTAGCGCTATCGCGCTTTT TTGGAAA-3'. \\ Antisense: 5' -CGCGTTTCCAAAAAAGCGCGATAG CGCTAATAATTTCTCGAGAAATTATTAGCGCT ATCGCGCGG-3'.}

After validation by sequencing, these expressing plasmids were co-transfected with three packaging plasmids (pLP1, pLP2 and pLP/VSVG) into $293 \mathrm{~T}$ packaging cell lines to produce lentivirus.

\section{Cell lines}

A549 adenocarcinomic human alveolar basal epithelial cells (ATCC) were infected with lentivirus to express human CD19 and ZsGreen simultaneously, and purified CD19 positive A549 cells were obtained by fluorescence activated cell sorting (FACS).

These cells were then infected with the pLenti-CMVluc2-IRES-Puro virus to express firefly luciferase. And the firefly luciferase stably expressing cells were established by puromycin selection. The Raji human Burkitt's lymphoma cells (ATCC) were engineered similarly to express luciferase.

\section{Preparation of CAR-T cells}

CAR-T cells were generated from donors' peripheral blood mononuclear cells (PBMCs). For T cells activation, $1 \mu \mathrm{g} /$ $\mathrm{ml}$ anti-CD3 monoclonal antibody (OKT3, Takara) was pre-coated overnight at $4{ }^{\circ} \mathrm{C}$ and $50 \mathrm{ng} / \mathrm{ml}$ anti-CD28 monocolonal antibody (CD28.2, Biolegend) was added into the medium. The PBMCs were activated for 2 days before infection. Infection was carried out by centrifugation at $850 \mathrm{~g}$ in a 24 -well plate at $31^{\circ} \mathrm{C}$ for 2 hours, and an agent called Envirus ${ }^{\mathrm{Tw}}-\mathrm{LV}$ (Engreen Biosystem) was applied to promote the infection efficiency. After infection, the CAR-T cells were cultured in GT-T551 medium (Takara) 
with $0.5 \%$ fetal bovine serum (FBS, Gibco) and $300 \mathrm{U} / \mathrm{ml}$ recombinant human IL-2 (rhIL-2, PeproTech).

In another culture protocol, $10 \mathrm{ng} / \mathrm{ml}$ recombinant human IL-7 (rhIL-7, PeproTech), $10 \mathrm{ng} / \mathrm{ml}$ recombinant human IL-15 (rhIL-15, PeproTech) and $10 \mathrm{ng} / \mathrm{ml}$ recombinant human IL-21 (rhIL-21, PeproTech) were used instead of IL-2.

\section{Quantitative real-time PCR}

The mRNA was reversed into cDNA using Transcriptor First Strand cDNA Synthesis Kit (Roche). Quantitative Real-Time PCR (qRT-PCR) was performed with FastStart Universal Real-Time PCR Master Mix (Roche) on Applied Biosystems 7500 systems. The primers were designed and synthesized by Life Technologies. The comparative Ct was normalized to the $\beta$-actin housekeeping gene as follows: $\Delta^{\mathrm{Ct}}($ sample $)=\mathrm{Ct}(\mathrm{PD}-1)-\mathrm{Ct}(\beta$-actin $)$. Then, the relative expression folds compared with control were calculated as follows: $2-\Delta \Delta \mathrm{Ct}=2^{\wedge}-(\Delta \mathrm{Ct}$ [sample] $-\Delta \mathrm{Ct}$ [control] $)$.

To test the intratumoral CAR copy numbers, the DNA from tumors was directly used as templates for qRT-PCR. The primers targeting a 153 base pair fragment containing portions of the CD8 a chain and adjacent CD137 chain wereused. To calculate the relative copy numbers folds, the sample with the highest $\Delta^{\mathrm{Ct}}$ in the S4-CART19 group on the seventh day was used as the control.

The following are the sequences of the primers used to detect PD-1 and CAR:

PD1-F-1:AGATCAAAGAGAGCCTGCGG,
PD1-R-1:CTCCTATTGTCCCTCGTGCG;
PD1-F-2:GTGTCACACAACTGCCCAAC,
PD1-R-2:CTGCCCTTCTCTCTGTCACC;
PD1-F-3:TGCAGCTTCTCCAACACATC,
PD1-R-3:CACGCTCATGTGGAAGTCAC;
CAR-F: GGTCCTTCTCCTGTCACTGGTT,
CAR-R:TCTTCTTCTTCTGGAAATCGGCAG.

Western blotting (WB) and immunofluorescence staining Seventy-two hours after infection, the $293 \mathrm{~T}$ cells were collected for WB or immunofluorescence staining. The antibody targeting CD3- $\zeta$ chain (ab119827, Abcam) was used to detect the CAR molecule.

After infection, ZsGreen positive Jurkat human $\mathrm{T}$ lymphocyte cells were sorted by FACS. After expansion, antibody targeting PD-1 (ab52587, Abcam) was used to detect the expression of PD-1.

\section{Flow cytometry}

All operations were performed in accordance with the manufacturer's recommended protocols. For detecting intracellular antigens, Foxp3/Transcription Factor Staining Buffer Set (00-5523-00, eBioscience) was used for fixation and perforation. The antibodies used in the text are as follows: mouse Fab fragment (115-065-072, Jackson ImmunoResearch), biotin (554061, BD pharmigen), PD-1 (329906, 329908 and 329938, Biolegend), PD-L1 (393610, Biolegend), CD3 (300308 and 300326, Biolegend), TIM-3 (345012, Biolegend), LAG-3 (369312, Biolegend), CD45RO (304210, Biolegend), CD62L (304840, Biolegend), CD107a (328620, Biolegend), IFN- $\gamma$ (502512, Biolegend) and Ki67 (350540, Biolegend). The 7-AAD (17501, AAT Bioquest) was used to detect apoptosis. DRAQ5 (65-088092, eBioscience) was used for live cells cell cycle assay.

Flow cytometry was performed on BD's Calibur II platform and the datas were analyzed by FlowJo software. For cell cycle analysis, the Modifit LT software was used.

\section{T cell function analysis}

To test the Ki67 and PD-1 expression upon target cells stimulation, $1 \times 10^{5}$ CAR-T cells and target cells were co-cultured for $12 \mathrm{~h}$ in 96 -well plate, and then the cells were subjected to flow cytometry analysis.

To test the expression of CD107a and IFN- $\gamma, 1 \times 10^{5}$ CAR-T cells and target cells were co-cultured for $4 \mathrm{~h}$ in 96-well plate. During the co-culture, Golgi inhibitors monensin (420701, Biolegend) and Brefeldin A (420601, Biolegend) were added. For CD107a analysis, the CD107a antibody was added into the medium at the beginning of the co-culture.

To test the released inflammatory factors, $1 \times 10^{5}$ purified CAR-T cells and target cells were co-cultured for $24 \mathrm{~h}$ in 96-well plate. Subsequently, the culture supernatant was used for multi-factor flow assay. Pre-defined panels of LEGENDplex (Biolegend) were used, and the LEGENDplex v8.0 software was used for analysis.

To test the in vitro proliferation, $0.4 \times 10^{4}$ purified CAR-T cells and $0.4 \times 10^{5}$ Raji-luc cells were co-cultured for $72 \mathrm{~h}$ in 96 -well plate. The absolute numbers of $\mathrm{T}$ cells were calculated by the following formula: total cell count $\times$ proportion of CD3 positive T cells.

To test the lysis of target cells, purified CAR-T cells were co-cultured with target cells at different $\mathrm{E}: \mathrm{T}$ ratios in 96-well plate. $100 \mu \mathrm{l} 2 \times$ D-Luciferin solution $(300 \mu \mathrm{g} / \mathrm{ml})$ were added into each well, and the signals were measured after $2-5$ min by Varioskan ${ }^{\text {Tax }}$ LUX (Thermo Fisher). The lysis was calculated by the following formula: 1-([value of sample]-[value of negative control])([value of positive control]-[value of negative control]).

\section{Mouse models}

We established intraperitoneally injected Raji-luc lymphoma and subcutaneously implanted A549-19luc solid tumor models, in which female NOD-Prkdc ${ }^{\text {scid }}-\mathrm{Il}_{2} \mathrm{rg}^{\text {null }}$ mice (NPG/Vst, VITALSTAR) aged 4 to 6 weeks were used. The volume of cells per injection was $100 \mu$ l. CAR-T cells were resuspended in PBS and injected through the 
tail vein. Tumor burdens were quantified by bioluminescence imaging (BLI) on NightOwl II (LB 983, Berthold) platform, BLI data was analyzed using indiGO software (Berthold); BLI signal was reported as average flux (photons per secondarea $\left[\mathrm{mm}^{2}\right]$ ). All animals were anesthetized with isoflurane gas.

For tracing the $\mathrm{T}$ cells in peripheral blood, approximately $200 \mu \mathrm{l}$ blood was taken through the canthus for subsequent flow analysis. To analyze the copy numbers of intratumoral CAR-T cells, the tumor masses were obtained by excision and fixed in formalin for subsequent qRT-PCR experiments.

\section{Statistics}

Data were analyzed using Prism v7.0 (GraphPad Software) and SPSS Statistics 24 (IBM). Survival curves were analyzed using the log-rank test. Statistical significance was defined as $P<0.05$.

\section{Study approval}

All animal experiments have been approved by the Institutional Animal Care and Use Committee (IACUC) of Chinese PLA General Hospital (PLAGH), and all the procedures were performed in accordance with the guidelines of IACUC of PLAGH.

\section{Results}

\section{Preparation of PD-1 knockdown CART-19 cells}

We constructed dual-promoter vectors those could express PD-1 targeting shRNA and CAR simultaneously, to which a ZsGreen motif was linked by a T2A motif. The expression of shRNA was driven by U6 promoter, and elongation factor 1-alpha (EF1- $\alpha$ ) was used to initiate the expression of CD19-targeting CAR (CAR19) (Fig. 1a).

The expression of CAR19 was confirmed by WB and immunofluorescence (Additional file 1: Figure S1A and B). As shown in Fig. 1b, a strict one-to-one correspondence between the expression of CAR and ZsGreen was presented, which allowed us to track and purify CAR-T cells by ZsGreen. The infection efficiency was between 15 and $25 \%$ on the third day after infection, and no significant difference between different constructs was demonstrated.

Six different PD-1 targeting shRNA sequences were synthesized to screen for valid ones, and a scramble sequence (SCR) was used as control. The PD-1 silencing efficiency was firstly analyzed in Jurkat cells by qRT-PCR, WB and flow cytometry (Additional file 1: Figure S1C, D and Fig. 1c) to exclude invalid shRNA sequences. Finally, we screened out two valid shRNA sequences, shRNA-3 (S3) and shRNA-4 (S4).

The functions of S3 and S4 were further confirmed in $\mathrm{T}$ cells. The expression of PD-1 was not significantly inhibited by S3 or S4 until the fourth day after lentivirus infection. On the seventh day of culture, which was the fifth day after viral infection, the PD-1 positive rates in S3 and S4 modified CART-19 (S3-CART19 and S4-CART19) cells decreased by about 72 and $88 \%$ respectively compared with that in the SCR modified CART-19 (SCR-CART19) cells (Fig. 1d).

In addition, we confirmed that the expression of PD-1 in SCR-CART19 cells would be significantly up-regulated by target cell-induced immune response (TCIIR) after 24 h co-culture with Raji cells (Additional file 1: Figure S1F). And the up-regulations could be effectively inhibited by S3 and S4 (Fig. 1e). The in vivo CAR and PD-1 expression in different CAR-T cells were also detected 7 days after CAR-T infusion (Additional file 1: Figure S3A). Most of the CD3-positive T cells expressed CAR molecule, and S3 and S4 could effectively inhibit the expression of PD-1.

Due to the more pronounced PD-1 silencing efficiency, S4 was chosen for the following functional tests.

\section{PD-1 knockdown did not enhance the cytotoxicity of CAR-T cells}

To evaluate the TCIIR potential, the expression of IFN- $\gamma$ and CD107a of CAR-T cells cultured for 7 days were detected after co-culture with Raji and CD19 positive A549 cells (A549-19). As shown in Fig. 2a and b, coculture induced a higher positive rates of IFN-yand CD107a in SCR-CART19 cells than that in S4-CART19 cells, and the strong expression of PD-L1 significantly inhibited CAR-T cells CD107a expression (Fig. 2b and Additional file 1: Figure S2). This indicated that PD-1 knockdown might impair CAR-T cells TCIIR in this short-time co-culture experiment. Moreover, the residual PD-1 could still exert significant inhibitory effect, and this was further confirmed by $\mathrm{CD} 107 \mathrm{a}$ expression test with A549-19 cells expressing moderate level of PD-L1 (Additional file 1: Figure S5D).

Inflammatory cytokines secretion is another important factor in determining anti-tumor activity. Multi-factor flow assay demonstrated that more IL-2 was secreted by S4-CART19 cells (cultured for 10 days). However, the secretions of the other tested factors were decreased by PD-1 knockdown. In this experiment, PD-1 knockdown significantly increased CAR-T cells resistance to PD-L1mediated immunosuppression (Fig. 2c).

To test the cell lysis directly, Raji and A549-19 cells expressing firefly luciferase (Raji-luc and A549-19luc) were established. Purified CAR-T cells (cultured for 10 days) were co-cultured with target cells for $24 \mathrm{~h}$. It was demonstrated that S4-CART19 and SCR-CART19 cells presented similar CAR-specific lysis of Raji-luc cells at higher E:T ratios. But at lower E:T ratios, 0.2:1 and 0.1:1, S4-CART19 cells was slightly, but with significance, less effective than SCR-CART19 cells (Fig. 2d). However, no 


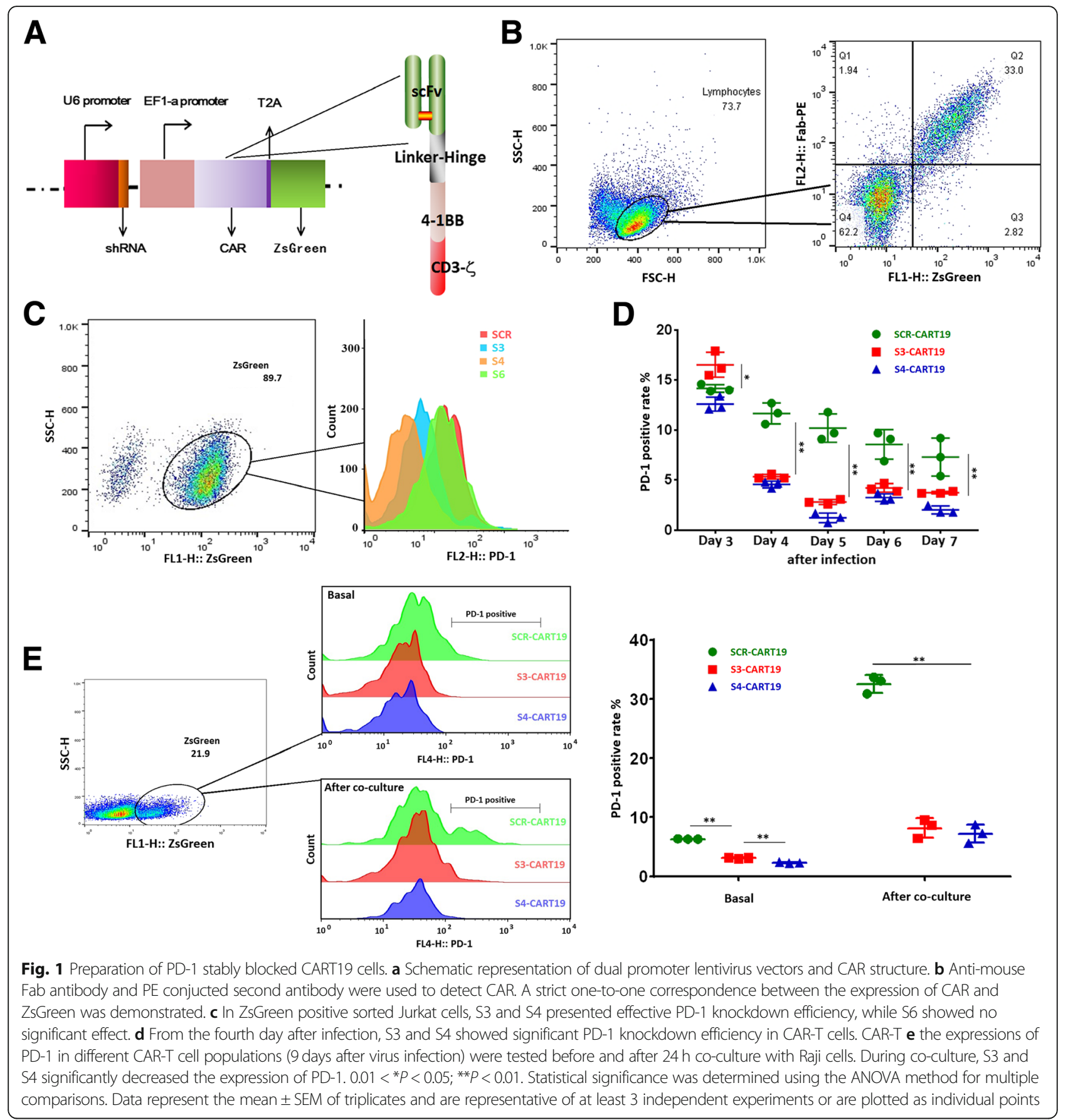

significant difference in lysis of A549-19luc or IFN- $\gamma$ stimulated A549-19luc cells between SCR-CART19 and S4-CART19 was demonstrated (Fig. 2e and f). We speculated that this might be because the cytokines released by $\mathrm{T}$ cells during co-culture up-regulated the expression of PD-L1 in A549 cells, and this was proved true by the results presented in Additional file 1: Figure S5C.

Taken together, these results indicated that PD-1 knockdown did not enhance the cytotoxicity of CAR-T cells, but instead impaired it under certain conditions.
Long-lasting PD-1 knockdown would impair the in vivo anti-tumor function of CAR-T cells

To evaluate the effect of long-lasting PD-1 knockdown on $\mathrm{T}$ cells, we conducted an in vivo experiment (Fig. 3a). In this xenograft model, $5 \times 10^{6}$ A549-19luc cells were implanted subcutaneously 2 weeks before CAR-T infusion. Tumor burdens across groups were equalized by BLI before CAR-T treatment. For CAR-T treatment, $1 \times 10^{6}$ sorted CAR-T cells cultured for 10 days were administered, and non-infected $\mathrm{T}$ cells were used as control. It 


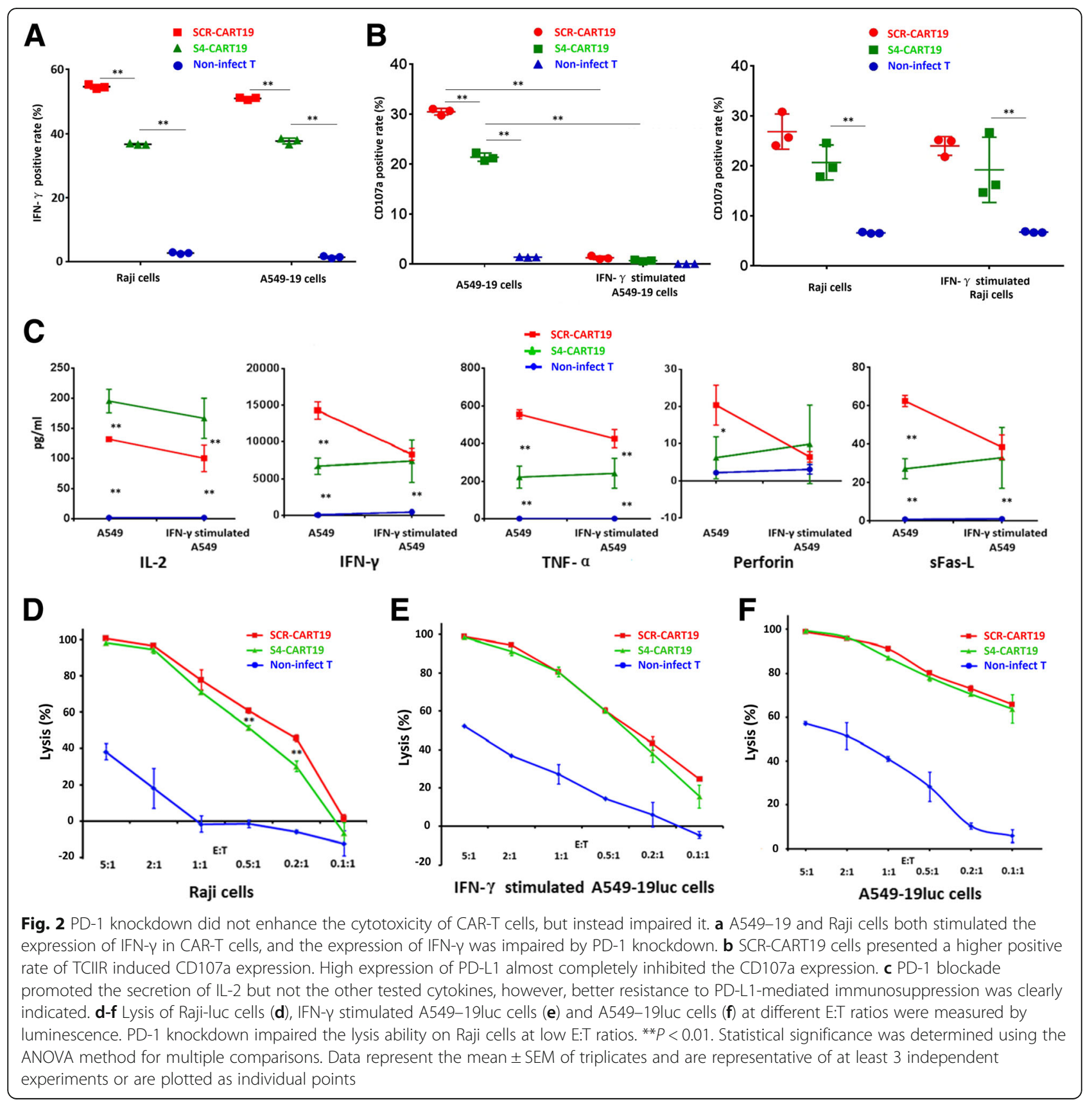

was found that SCR-CART19 cells could rapidly eradicate tumors, and no tumor recurrence was detected during the following 2 months observation. Better anti-tumor function of S4-CART19 cells was not observed, on the contrary, the tumor clearance was significant slower and weaker (Fig. 3a, b and Additional file 1: Figure S3B). All the treated mice exhibited little $\mathrm{T}$ cells expansion, except for one receiving SCR-CART19 cells developed significant $\mathrm{T}$ cells amplification 3 weeks after CAR-T cells infusion (Fig. 3c and Additional file 1: Figure S3C). The survival statistics showed that the mice treated with S4-CART19 cells did not have prolonged survival compared with those treated with SCR-CART19 cells (Fig. 3d).

These results suggested that long-lasting PD-1 silencingmight impair the in vivo anti-tumor function of CAR-T cells.

\section{PD-1 knockdown impaired CAR-T cells in vitro proliferative potential}

Proliferation is a key factor in determining CAR-T cells' anti-tumor potential [24]. In previous in vivo experiments, the effect of PD-1 knockdown on $\mathrm{T}$ cell 


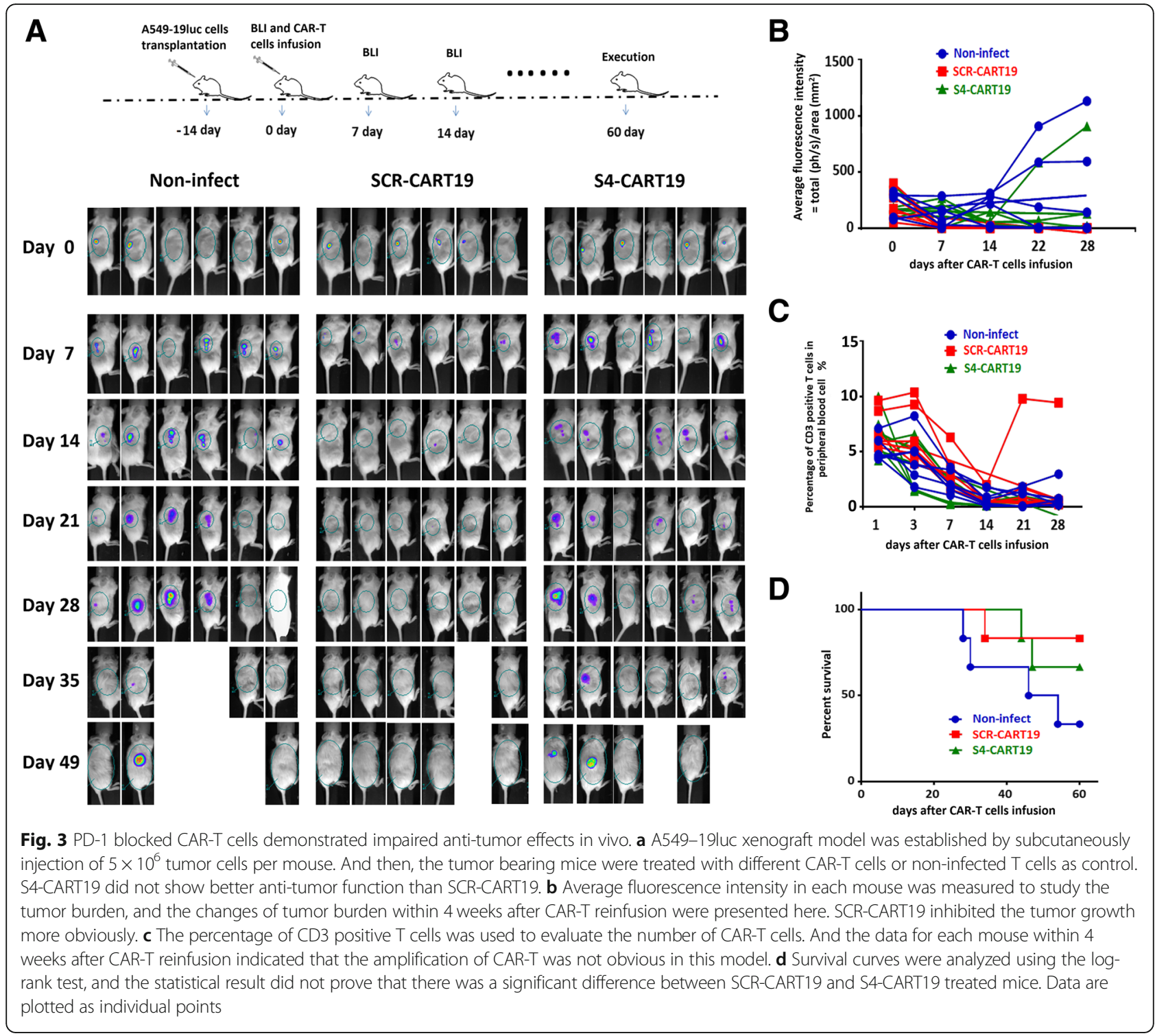

proliferation was not demonstrated due to the insufficient expansion of CAR-T cells. Therefore, we conducted more specific in vitro experiments to study the proliferative capacity of CAR-T cells.

First, $0.4 \times 10^{4}$ purified CAR-T cells cultured for 10 days were co-cultured with Raji-luc cells at a low E:T ratio (0.1:1) for 3 days. The tumor lysis by S4-CART19 cells was found to be significantly impaired compared with SCR-CART19 cells (Fig. 4a). Meanwhile, the amplification times of S4-CART19 cells was only about onethird of that of SCR-CART19 cells (Fig. 4b), indicating that the amplification driven by TCIIR was impaired.

Next, we tested the expression of ki67 in CAR-T cells to further elucidate the proliferative potential. It was confirmed that the ki67 positive rate of S4-CART19 cells was lower than that of SCR-CART19 cells not only after but also before TCIIR (Additional file 1: Figure S4A).
This suggested that CAR-T cells proliferation driven by cytokines might be also impaired by PD-1 silencing. This conclusion was conflicting to the widely accepted view that PD-1 receptor was detrimental to T cells proliferation [25]. We doubted whether the shRNA4 sequence mistakenly targeted other genes involved in cell proliferation. To exclude this possibility, another PD-1 targeting shRNA sequence, S3, was tested to verify the results' authenticity.

We examined the expression of ki67 in CAR-T cells those were cultured for fourteen days. The results showed that S3 could produce similar effects on CAR-T cells as S4, although the effect was a little weaker (Additional file 1: Figure S4B).

By continuously tracking the ZsGreen positive rates during cultivation, we further confirmed that the proliferations of S3-CART19 and S4-CART19 cells were both 


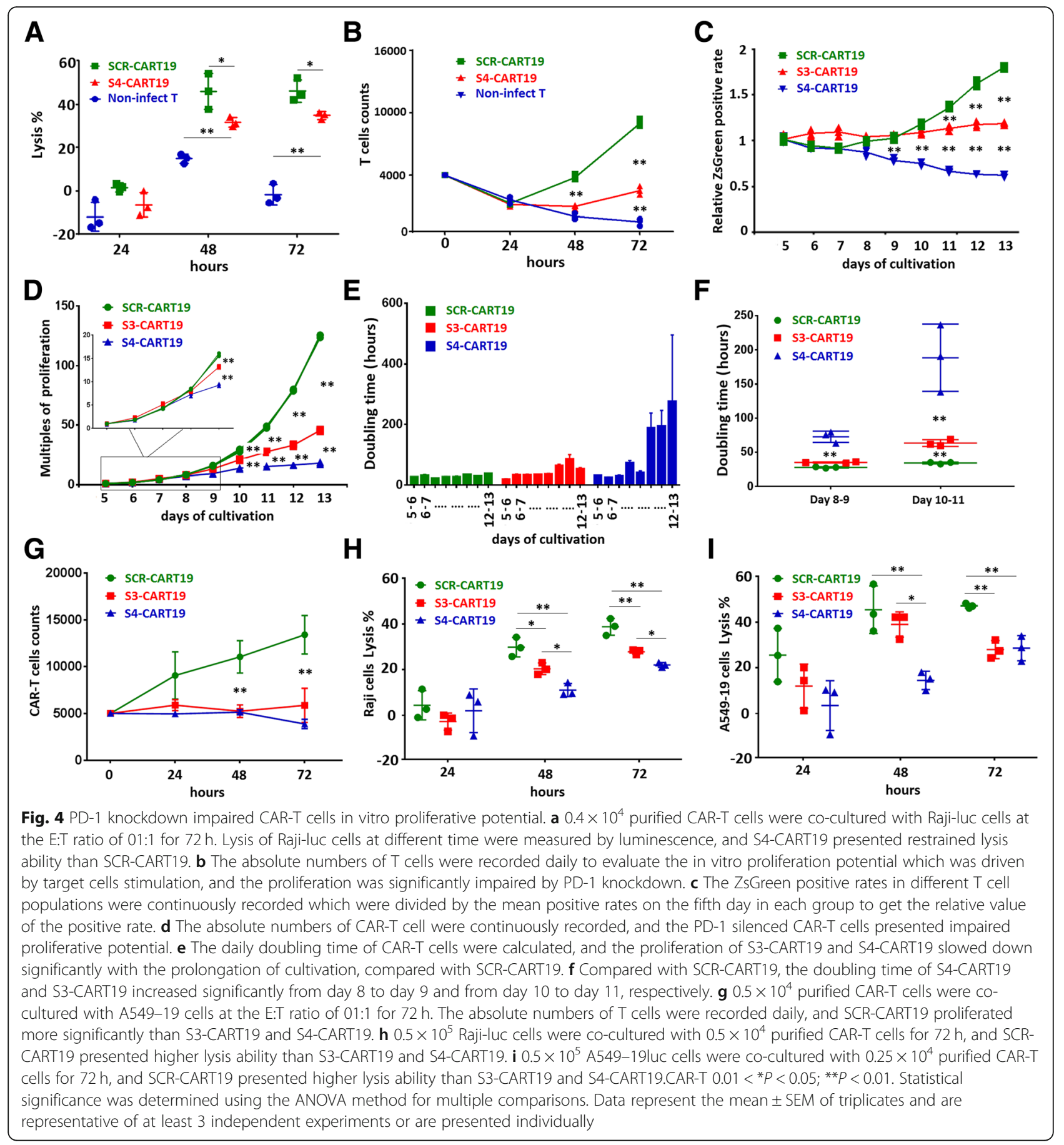

damped, but the attenuation in S3-CART19 cells was delayed and more moderate than S4-CART19 cells (Fig. 4c). By calculating the absolute number of CAR-T cells, it was found that on the ninth day of culture (day 7 after viral infection), the proliferation multiples of S3-CART19 and S4-CART19 began to be significantly lower than SCRCART19 (Fig. 4d). The daily doubling time was also calculated, and the proliferation of PD-1 silenced CAR-T cells became slower and slower with the prolongation of cultivation (Fig. 4e). Compared with SCR-CART19, the obvious prolongation of doubling time in S4-CART19 and S3-CART19 first appeared on day 8 to day 9 and on day 10 to day 11, respectively (Fig. 4f). Cell cycle assays also demonstrated that the proliferative potential during 
cultivation was impaired by PD-1 silencing, and the effect of S3 was weaker than that of S4 (Additional file 1: Figure $S 4 C$ and $D$ ).

The 7-AAD staining results indicated that the decrease of PD-1 silenced CAR-T cells in total population was not due to increased apoptosis (Additional file 1: Figure S5A). We detected several genes most likely to be mistargeted by $\mathrm{S} 3$ or S4, and the qRT-PCR data further confirmed the specificity of S3 and S4 (Additional file 1: Figure S6).

The proliferation of S3-CART19 and S4-CART19 driven by co-culture with A549-19 cells (PD-L1 would be significantly up-regulated) were also tested. $0.5 \times 10^{4}$ purified CAR-T cells were co-cultured with A549-19 cells at the E:T ratio of 01:1 for $72 \mathrm{~h}$. The absolute T cell numbers were recorded daily, and SCR-CART19 presented more significant proliferation than S3-CART19 and S4-CART19 (Fig. 4g). The $72 \mathrm{~h}$ lysis analysis (E:T at 0.1:1 for Raji-luc cells and E:T at 0.05:1 for A549-19luc cells) demonstrated that SCR-CART19 presented higher lysis ability than S3-CART19 and S4-CART19 (Fig. 4h and i).

Taken together, these results demonstrated that PD-1 silencing in CAR-T cells would impair their proliferative potential, as well as the authenticity of this finding.

\section{T cells' differentiation kinetics was altered by PD-1 knockdown}

Differentiation status plays a decisive role in $\mathrm{T}$ cell proliferation. We assessed CAR-T cells' senescence by detecting the expression of TIM3 and LAG3. It was found that PD1 knockdown did not up-regulate the expression of TIM3 or LAG3, but decreased them. Meanwhile, this effect was more pronounced in S4-CART19 cells compared with S3CART19 cells (Fig. 5a and b). During cultivation, T cells would gradually differentiate from early-differentiation status into late-differentiation status, and the proliferative capacity would also gradually decrease [26]. We labeled CD62L and CD45RO for CD8-positive T cells to analyze their differentiation status. Typically, $\mathrm{CD}^{2} \mathrm{~L}^{+} \mathrm{CD}_{45 \mathrm{RO}^{-} \mathrm{T}}$ cells are considered to be naive $\mathrm{T}$ cells. As differentiation progresses, $\mathrm{T}$ cells would become $\mathrm{CD}_{2} 2 \mathrm{~L}^{+} \mathrm{CD} 45 \mathrm{RO}^{+}$central memory T cells and CD62 $\mathrm{L}^{-} \mathrm{CD} 45 \mathrm{RO}^{+}$effector T cells. Although there are some different opinions about the status of $\mathrm{CD}^{2} 2 \mathrm{~L}^{-} \mathrm{CD} 45 \mathrm{RO}^{-} \mathrm{T}$ cells, we tend to believe that these cells are effector memory $\mathrm{T}$ cells derived from effector T cells.

As shown in Fig. 5c and Additional file 1: Figure S5E and F, during the cultivation, knockdown of PD-1 significantly accelerated CAR-T cells' differentiation into $\mathrm{CD}^{2} 2 \mathrm{~L}^{-} \mathrm{CD} 45 \mathrm{RO}^{+}$ $\mathrm{T}$ cells. In particular, the naive T cells in S3-CART19 and S4-CART19 faded rapidly. Meanwhile, PD-1 knockdown appeared to prevent further differentiation of $\mathrm{CD} 2 \mathrm{~L}^{-} \mathrm{CD} 45 \mathrm{RO}^{+} \mathrm{T}$ cells into $\mathrm{CD}^{-} \mathrm{L}^{-} \mathrm{CD}^{-} 5 \mathrm{RO}^{-} \mathrm{T}$ cells. By analyzing ZsGreen negative $\mathrm{T}$ cells (non-infected $\mathrm{T}$ cells) in the same cell populations (cultured for ten days), we excluded the possibility that different culture conditions caused this difference (Additional file 1: Figure S5B).

Next, the effect of PD-1 silencing on exhausted CART cells was studied. Raji-luc cells were added at E: $\mathrm{T}=1: 3$ on the 5th day of culture (single stimulation, SST) or on the 5th and 8th day of culture (double stimulation, DST) to induce $\mathrm{T}$ cell exhaustion. As shown in Fig. $5 d$, e and $\mathrm{f}$, DST induced more significant exhaustion phenotype than SST, proofed by higher up-regulation of TIM-3 and LAG-3 and lower TCIIR induced CD107a expression. Of note, PD-1 knockdown seemed to retard T cell exhaustion during SST and DST. However, after DST, the antitumor functions of PD-1 knockdown CAR-T cells were still weaker than that of SCR-CART19 cells (Fig. 5g).

The effect of long-lasting PD-1 blockade by antibodies was also observed. We found that the antibodies barely altered the expressions of TIM-3 or LAG-3, differentiation kinetics and proliferative ability (Fig. 5h, i and Additional file 1: Figure S7). This suggested that simply blocking PD-L1/PD-1 interaction ( $\mathrm{T}$ cells also express PD-L1, Additional file 1: Figure S1E) was quite different from intrinsic PD-1 silencing.

Taken together, we confirmed that PD-1 knockdown but not antibody-mediated blockade altered CAR-T cells' differentiation kinetics.

\section{PD-1 knockdown impaired in vivo persistence and proliferation of CAR-T cells}

Persistence is another key factor determining CAR-T cells' function [24]. To evaluate the persistence, we administered $1 \times 10^{6}$ purified CAR-T cells or non-infected $\mathrm{T}$ cells per mouse. After 2 weeks of feeding, these mice were inoculated with $2 \times 10^{7}$ A549-19luc cells subcutaneously. As shown in Fig. 6a, little tumor growth was observed in each group during the first 2 weeks after inoculation. During the next 2 weeks, tumors in control group grew rapidly. In comparison, the residual S3-CART19 and S4-CART19 cells limited tumor growth effectively, but the limitation was significantly less effective than that of SCR-CART19 cells (Fig. 6a and b). This suggested the persistence of CAR-T cells might be impaired by PD-1 knockdown.

In previous in vivo experiments, CAR-T cells did not show significant expansion, which might be due to the limited contacts between CAR-T cells and transplanted tumors. Therefore, we planned to use a hematological tumor model in which the contacts were sufficient to study the $\mathrm{T}$ cells proliferation. In this model, $1 \times 10^{6}$ Raji-luc cells were inoculated 1 week before the CAR-T treatment (Fig. 6c). After equalization by BLI, $5 \times 10^{5}$ CAR-T cells that were cultured for 10 days were given. As shown in Fig. 6d, the infused $T$ cells reached a numerical peak on the third day after treatment (including 


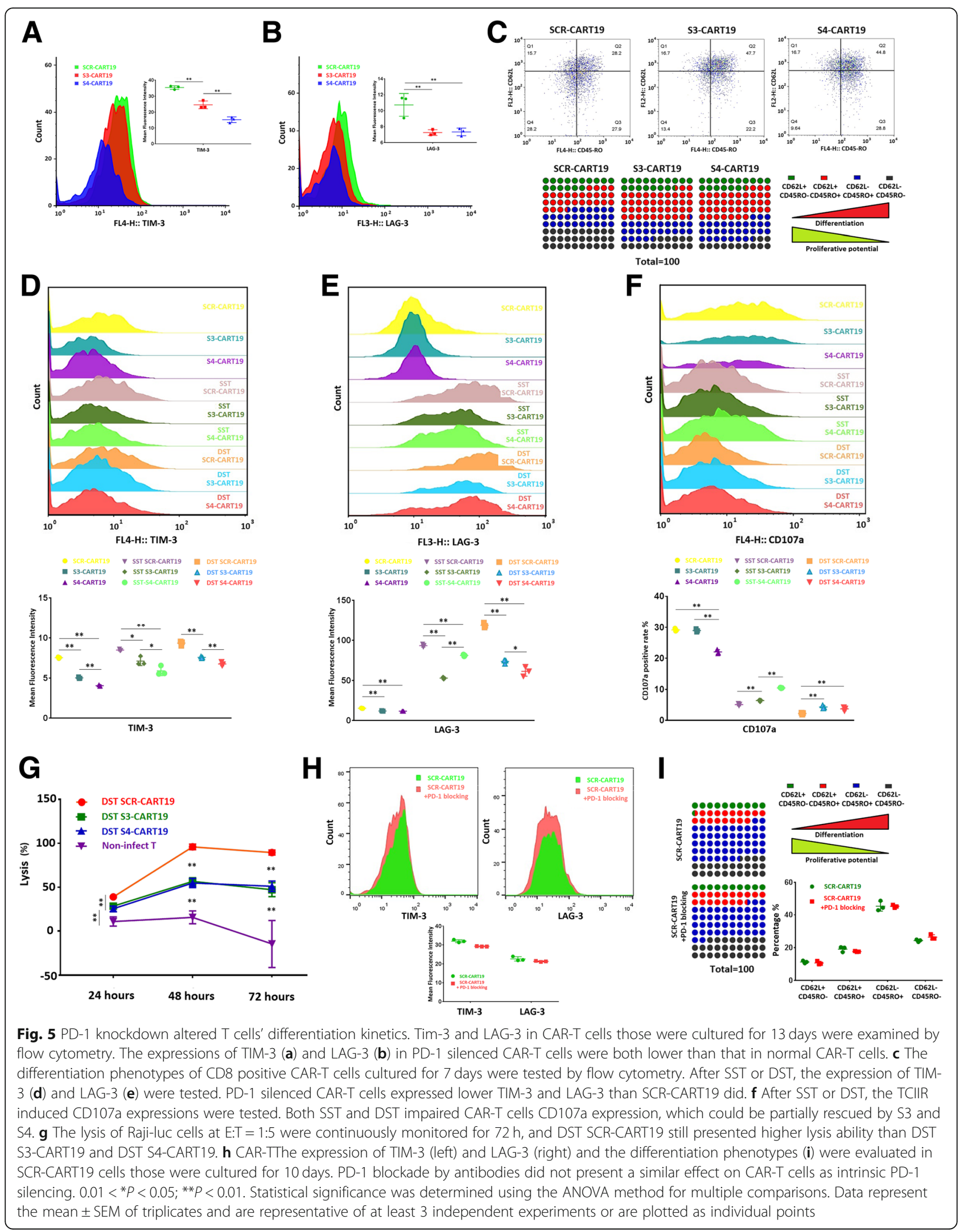




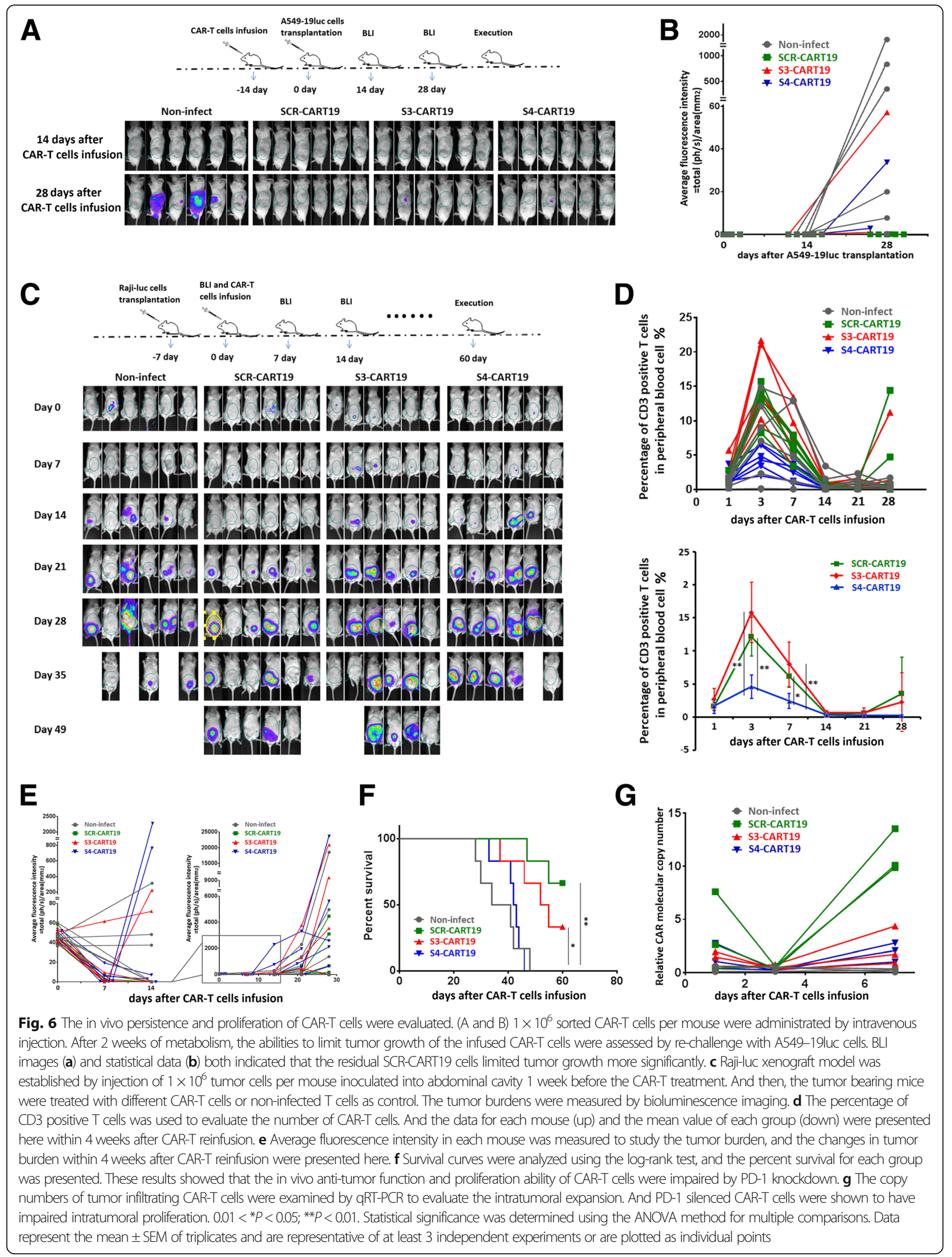


the non-infected $\mathrm{T}$ cells) and then gradually fell back. In the fourth week after treatment, significant secondary amplifications of CAR-T cells were observed in two SCR-CART19 treated and one S3-CART19 treated mice. The statistical results showed that the expansion of S4CART19 cells was significantly lower than that of SCRCART19 and S3-CART19 cells. Tumor cells could be rapidly erased in almost all the CAR-T treated mice during the first week of treatment. During the second week, tumor clearance persisted in the SCR-CAR-T group, meanwhile, significant tumor growth was observed in both S3-CART19 and S4-CART19 groups. During the following 2 weeks, tumor burdens increased rapidly in all groups, but SCR-CART19 cells presented better antitumor function than S3-CART19 and S4-CART19 cells (Fig. $6 \mathrm{c}$ and e). And the survival statistics was consistent this view (Fig. 6f).

Considering that PD-L1-mediated immunosuppression could be partially rescued by PD-1 blockade, different amplification potential might be presented by solid tumor infiltrating CAR-T cells. To study the intratumoral expansion, $1 \times 10^{7}$ A549-19luc cells were implanted subcutaneously. Three weeks later, the tumors, of which the diameters were about $1 \mathrm{~cm}$, were equalized by BLI. And then $1 \times 10^{6}$ purified CAR-T cells which were cultured for 10 days were given. After infusion, the qRT-PCR results showed that infiltrating CAR-T cells showed a significant proliferation on day 7 after a decline on day 3. The mean copy number of SCR-CART19 cells was significantly higher, about five times, than that of the S3-CART19 and S4-CART19 cells (Fig. 6g). This suggested that the intratumoral amplification was also impaired significantly by PD1 silencing.

\section{The effects of PD-1 knockdown were prevalent in different culture conditions and CAR-T systems}

Limited proliferation potential is one of the hallmarks of $\mathrm{T}$ cell exhaustion and this could be promoted or rescued by many factors [27].

It has been reported that cytokines such as IL-7, IL-15 and IL-21 can retard T cell senescence, and promote differentiation into memory phenotype and proliferation [28-30]. We confirmed that the combined use of these cytokines did enhance the proliferative activity, but the proliferation inhibition caused by PD-1 knockdown could not be rescued (Fig. 7a). Meanwhile, the alteration of differentiation kinetics caused by PD-1 knockdown was still present here (Fig. 7b).

It has been reported that $\mathrm{T}$ cells exhaustion could be triggered by unique conformation of CAR19 molecule mediated autonomous activation [31]. To verify whether the impairment of proliferation caused by PD-1 knockdown was also present in other CAR-T systems, we constructed and tested epidermal growth factor receptor
(HER-1) targeting CART (SCR-CART-HER1, S3-CARTHER1 and S4-CART-HER1) cells. As shown in Fig. 7c and $\mathrm{d}$, the proliferation potential of CART-HER1 cells was also inhibited by intrinsic PD-1 blockade, and the alteration of phenotypes was similar to that observed in CART-19 cells.

\section{Discussion}

We wondered whether PD-1 blockade is monotonously beneficial to $\mathrm{T}$ cells, especially when the blockade is long-lasting. To prove this point, we constructed dualpromoter vectors that could ensure a clear study of the relationship between PD-1 blockade and CAR-T functions. With this system, we demonstrated that PD1 knockdown would impair the anti-tumor potential and proliferation of CAR-T cells. During in vitro cultivation, the PD-1 silencing altered the differentiation kinetics, and the persistence of CAR-T cells was also attenuated. These findings suggested that PD-1 might not be unfavorable for $\mathrm{T}$ cells function invariably. Moreover, it might be essential for maintaining normal proliferative activity and anti-tumor function. This result will inspire us to re-recognize the function of PD-1 and have certain significance for guiding the clinical use of PD-1 blocking therapies.

Previously, several articles have practiced the strategy of intrinsic blockade of PD-1 in T cells with CRISPR/Cas9 or shRNA technologies [17, 32-34]. Their conclusions were inconsistent with ours. In fact, our colleagues in another group had also confirmed that the anti-tumor function of CAR-T cells would be improved by PD-1 knockout. Therefore, we carried out a clinical trial using PD-1 knockout mesothelin-CAR-T cells (NCT03747965).

We speculate that this discrepancy may be caused by the following reasons. First, differences in the intensity of PD-L1 expression may cause bias. If PD-L1 is constantly over-expressed, low levels of PD-1 expression (by knockdown) may still have a sustained and significant inhibitory effect. And we have also observed such a hint (Fig. $2 \mathrm{~b}$ and Additional file 1: Figure S5C and D),

Second, the PD-1 receptor has two different signaling motifs, immunoreceptor tyrosine-based inhibitory motif (ITIM) and immunoreceptor tyrosine-based switch motif (ITSM). However, whether these motifs work cooperatively or independently is still unknown. In addition, the current evidence suggests that only ITSM but not ITIM is involved in the recruitment of downstream inhibitory molecules, even though both of them are phosphorylated upon activation [35]. Does PD-1 have other functions rather than inhibition? Can it function independently of ligands? In fact, these very reasonable assumptions have been ever proposed or partially verified [23]. We speculate that the knockdown of PD-1 might break its balance of normal functions, and the residual PD-1 receptors may 


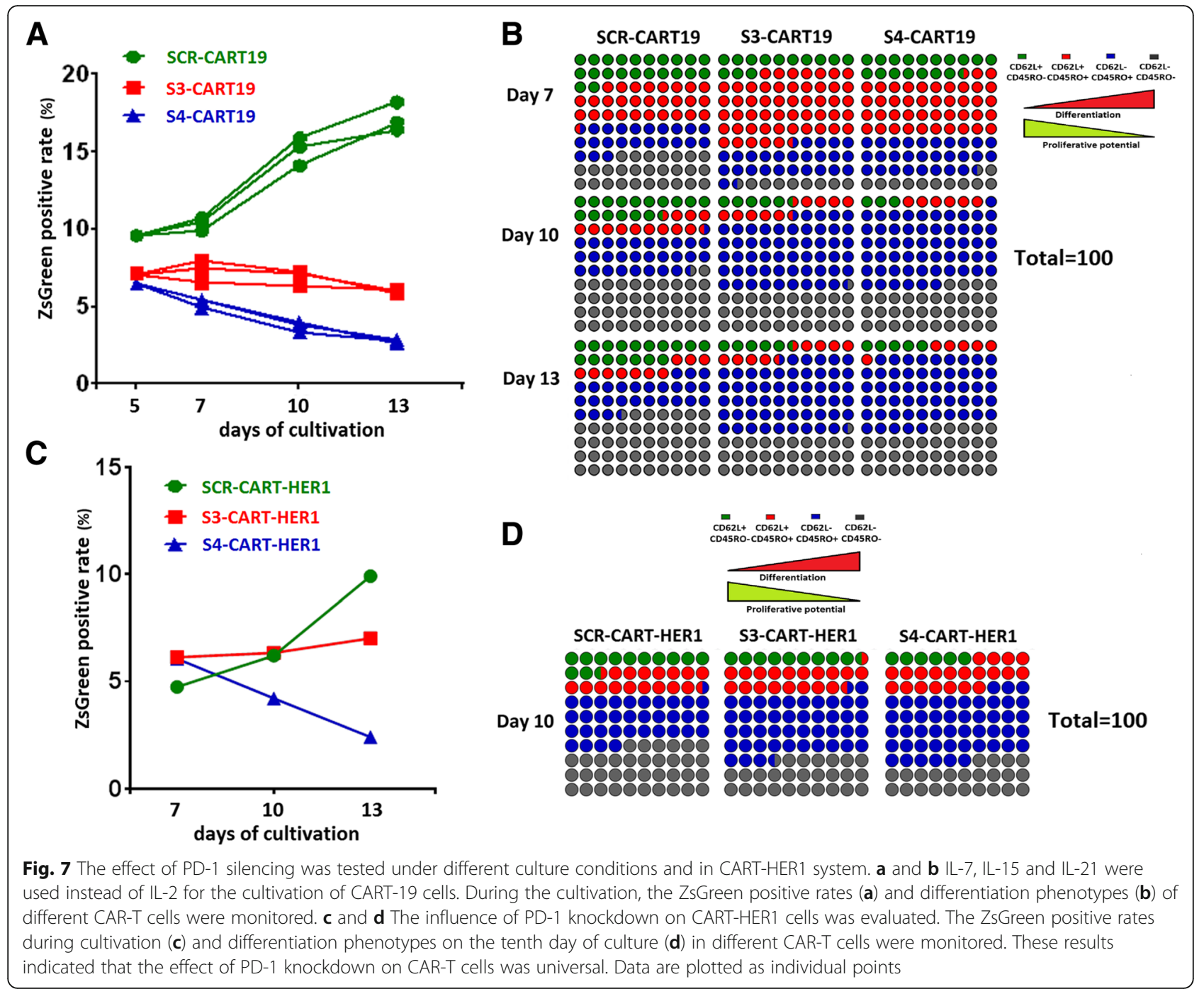

still exert specific regulatory signaling. We believe that this may be the main reasons for the inconsistency between PD-1 knockout and knockout. Although knockdown and knockout are often used to verify each other, the results observed by these two methods sometimes still lead to inconsistent conclusions [36].

Although there was ample evidence that PD-1 knockdown inhibited T cell proliferation, S3-CART19 cells still exhibited a similar in vivo proliferative capacity as SCRCART19 cells. We thought that this inconsistency might be due to the experimental bias. In the S3-CART19 treatment group, two mice developed abnormally CAR-T amplification than the other samples (Fig. 6d). This bias could be caused by differences in the initial tumor burdens and the administrated CAR-T cell numbers. In addition to proliferation, we also observed that PD-1 knockdown altered the differentiation of CAR-T cells. It seemed that PD-1 knockdown accelerated the early differentiation but prevented effector $\mathrm{T}$ cells from entering into effector memory
$\mathrm{T}$ cells. We speculate that this may be the cause of impaired proliferation of CAR-T cells. Because the killing activity of late-differentiated $\mathrm{T}$ cells is more robust, the slightly weaker TCIIR presented by PD-1 knockdown CAR-T cells may be due to the changes in T cell composition (lower proportion of CD62 $\mathrm{L}^{-} \mathrm{CD} 45 \mathrm{RO}^{-} \mathrm{T}$ cells).

Compared with IL-2, the combination of IL-7, IL-15 and IL-21 significantly increased not only the proportion of early-differentiated $\mathrm{T}$ cells, but also the proportion of late-differentiated $\mathrm{T}$ cells. Considering that these factors can help $\mathrm{T}$ cells maintain a younger status and promotes $\mathrm{T}$ cell proliferation activity, we speculate that the early differentiation of $\mathrm{T}$ cells is more influenced by signaling, and the late differentiation is more dependent on the cell divisions.

Although we have demonstrated that PD-1 knockdown inhibited the anti-tumor function of CAR-T cells, we still do not insist that the clinical application of PD-1 blockade is discouraging. First, the activation of 
endogenous CTLs depends on the interaction of T-cell receptor (TCR) and human leukocyte antigen (HLA) complexes and co-stimulatory molecules, and this natural activation process is normally not as abundant as the artificial one. In addition, the immune response induced by natural TCR-HLA interaction is usually milder than that mediated by CAR molecule [37-39]. Although we have reached the same conclusion with different culture protocols and CAR-T systems, we would like to emphasize that this may not apply to all long-lasing PD-1 blockade scenarios, because long-lasting PD-1 blockade are likely to develop different influences on $\mathrm{T}$ cells in different statuses [22, 40].

Second, the difference between intrinsic and antibodydependent PD-1 blockade is obvious. This also suggested that PD-1 might directly regulate $\mathrm{T}$ cells but not rely on the involvement of PD-L1. In this scenario, the long-lasting PD-1 blockade by antibody would not perturb the innate function of PD-1, and the antibody drugs would be still promising.

Third, the effect of PD-1 blockade on improving T cell resistance to immunosuppression is undoubted. If the key mechanism by which PD-1 knockdown impairs $\mathrm{T}$ cell proliferation could be validated, other strategies could be combined to rescue the adverse effects. And this is the subject we will focus on next.

\section{Conclusions}

Whether PD-1 blockade is monotonously beneficial to T cells remains controversial, especially when the blockade is long-lasting. To improve our understanding of longlasting PD-1 blockade, we constructed dual-promoter vectors in which $\mathrm{PD}-1$ blockade and CAR molecule expression could be achieved within individual cells to guarantee a clear study of the relationship between PD-1 blockade and $\mathrm{T}$ cell functions. With this system, we demonstrated that PD1 knockdown would impair the in vitro and in vivo anti-tumor potential and proliferation of CAR-T cells. During in vitro cultivation, the PD-1 silencing altered the differentiation kinetics. The persistence of CAR-T cells was also attenuated by PD-1 silencing. These findings suggested that PD-1 signaling might not be unfavorable for $\mathrm{T}$ cells function invariably. Moreover, it might be essential for maintaining normal proliferative activity and anti-tumor function. This result will inspire us to re-recognize the function of PD-1 and have certain significance for guiding the clinical use of PD-1 blocking therapies.

\section{Additional file}

Additional file 1 Figure S1. Confirmation of the function of the dual promoter vectors. Figure S2. Expression of PD-L1 in different tumor cells. Figure S3. In vivo expression of CAR molecules and PD-1, tumor burdens and in vivo expansion of CAR-T cells. Figure S4. Analysis of in vitro proliferative potential of CAR-T cells. Figure S5. The effect of PD-1 knockdown on CAR-T cell function and differentiation status. Figure S6. The expression of several potential off-targeted genes. Figure S7. PD-1 blocking antibodies barely affect the phenotype and proliferation of CART cells. (DOCX $3914 \mathrm{~kb})$

\section{Abbreviations}

BLI: Bioluminescence imaging; CAR-T: Chimeric antigen receptor modified T; CTL: Cytotoxic T Iymphocytes; DST: Double stimulation; E:T: Effector cell to target cell; EF1-a: Elongation factor 1-alpha; HPD: Hyperprogressive disease; LAG-3: Lymphocyte activation gene-3; PBMC: Peripheral blood mononuclear cells; PD-1: Programmed death-1; PD-L1: Programmed death-ligand 1; qRTPCR: Quantitative real-time PCR; S3: shRNA-3; S4: shRNA-4; SCR: Scramble sequence; shRNA: Short hairpin RNA; SST: Single stimulation; TCIIR: Target cellinduced immune response; TIM-3: Mucin-domain containing-3; WB: Western blotting

\section{Acknowledgements}

Not applicable.

\section{Authors' contributions}

JSW, CL and WDH conceived and designed the study. JSW, ZQW and CL conducted the experiments. JSW analyzed and interpreted the data. ZQW provided the CAR19 sequences. JSW, ZQW and WDH wrote the manuscript. YW, YLG, HRD, DDT and CT provided administrative, technical, or material support. ZQW and WDH supervised the study. All authors read and approved the final manuscript.

\section{Funding}

This research was supported by the grants from the National Natural Science Foundation of China (No. 81830002 and 31870873 to WDH, No. 81703044 to JSW and No. 81502679 to CL) and the National Key Research and Development Program of China (No. 2016YFC1303501 and 2016YFC1303504 to WDH and No.2017YFC0909803 to YW). These financial supports were mainly used to purchase laboratory reagents and laboratory animals.

Availability of data and materials

All data generated or analyzed in this study are included in this article and its additional files. Other data that are relevant to this article are available from the corresponding author upon reasonable request.

\section{Ethics approval and consent to participate}

All animal experiments have been approved by the Institutional Animal Care and Use Committee (IACUC) of Chinese PLA General Hospital (PLAGH), and all the procedures were performed in accordance with the guidelines of IACUC Of PLAGH.

\section{Consent for publication}

No individual data were used in this study.

\section{Competing interests}

The authors declare that they have no competing interests.

Received: 26 November 2018 Accepted: 18 July 2019 Published online: 07 August 2019

\section{References}

1. Garfall AL, Maus MV, Hwang WT, Lacey SF, Mahnke YD, Melenhorst JJ, et al. Chimeric antigen receptor T cells against CD19 for multiple myeloma. N Engl J Med. 2015;373(11):1040-7.

2. Zhang WY, Wang Y, Guo YL, Dai HR, Yang QM, Zhang YJ, et al. Treatment of CD20-directed chimeric antigen receptor-modified T cells in patients with relapsed or refractory B-cell non-Hodgkin lymphoma: an early phase lla trial report. Signal Transduct Target Ther. 2016;1:16002.

3. Ali SA, Shi V, Maric I, Wang M, Stroncek DF, Rose JJ, et al. T cells expressing an anti-B-cell maturation antigen chimeric antigen receptor cause remissions of multiple myeloma. Blood. 2016;128(13):1688-700. 
4. Maude SL, Frey N, Shaw PA, Aplenc R, Barrett DM, Bunin NJ, et al. Chimeric antigen receptor T cells for sustained remissions in leukemia. N Engl J Med. 2014;371(16):1507-17.

5. Wang Z, Guo Y, Han W. Current status and perspectives of chimeric antigen receptor modified T cells for cancer treatment. Protein Cell. 2017:8(12):896-925.

6. Newick K, O'Brien S, Moon E, Albelda SM. CAR T cell therapy for solid tumors. Annu Rev Med. 2017:68:139-52.

7. Dai H, Wang Y, Lu X, Han W. Chimeric antigen receptors modified T-Cells for cancer therapy. J Natl Cancer Inst. 2016;108(7). https://academic.oup. com/jnci/article/108/7/djv439/2412501.

8. Ribas A. Tumor immunotherapy directed at PD-1. N Engl J Med. 2012; 366(26):2517-9.

9. Chen G, Huang AC, Zhang W, Zhang G, Wu M, Xu W, et al. Exosomal PD-L1 contributes to immunosuppression and is associated with anti-PD-1 response. Nature. 2018;560(7718):382-6.

10. Freeman GJ, Long AJ, Iwai $Y$, Bourque $K$, Chernova $T$, Nishimura $H$, et al. Engagement of the PD-1 immunoinhibitory receptor by a novel B7 family member leads to negative regulation of lymphocyte activation. J Exp Med. 2000;192(7):1027-34

11. Latchman Y, Wood CR, Chernova T, Chaudhary D, Borde M, Chernova I, et al. PD-L2 is a second ligand for PD-1 and inhibits T cell activation. Nat Immunol. 2001;2(3):261-8.

12. Gubin MM, Zhang $X$, Schuster $H$, Caron E, Ward JP, Noguchi T, et al. Checkpoint blockade cancer immunotherapy targets tumour-specific mutant antigens. Nature. 2014;515(7528):577-81.

13. Tumeh PC, Harview $\mathrm{CL}$, Yearley JH, Shintaku IP, Taylor EJ, Robert $L$, et al. PD1 blockade induces responses by inhibiting adaptive immune resistance. Nature. 2014;515(7528):568-71.

14. Ribas A, Shin DS, Zaretsky J, Frederiksen J, Cornish A, Avramis E, et al. PD-1 blockade expands Intratumoral memory T cells. Cancer Immunol Res. 2016; 4(3):194-203.

15. Kamphorst AO, Wieland A, Nasti T, Yang S, Zhang R, Barber DL, et al. Rescue of exhausted CD8 T cells by PD-1-targeted therapies is CD28-dependent. Science. 2017;355(6332):1423-7.

16. Chong EA, Melenhorst JJ, Lacey SF, Ambrose DE, Gonzalez V, Levine BL, et al. PD-1 blockade modulates chimeric antigen receptor (CAR)-modified T cells: refueling the CAR. Blood. 2017;129(8):1039-41.

17. Cherkassky L, Morello A, Villena-Vargas J, Feng Y, Dimitrov DS, Jones DR, et al. Human CAR T cells with cell-intrinsic PD-1 checkpoint blockade resist tumor-mediated inhibition. J Clin Invest. 2016;126(8):3130-44.

18. Su S, Hu B, Shao J, Shen B, Du J, Du Y, et al. CRISPR-Cas9 mediated efficient PD-1 disruption on human primary $T$ cells from cancer patients. Sci Rep. 2016;6:20070.

19. Koyama S, Akbay EA, Li YY, Herter-Sprie GS, Buczkowski KA, Richards WG, et al. Adaptive resistance to therapeutic PD-1 blockade is associated with upregulation of alternative immune checkpoints. Nat Commun. 2016;7:10501

20. Wang Q, Wu X. Primary and acquired resistance to PD-1/PD-L1 blockade in cancer treatment. Int Immunopharmacol. 2017;46:210-9.

21. Brower V. Hyperprogressive disease with anti-PD-1 and anti-PD-L1. Lancet Oncol. 2016;17(12):e527.

22. Champiat S, Dercle L, Ammari S, Massard C, Hollebecque A, Postel-Vinay S, et al. Hyperprogressive disease is a new pattern of progression in Cancer patients treated by anti-PD-1/PD-L1. Clin Cancer Res. 2017;23(8):1920-8.

23. Odorizzi PM, Pauken KE, Paley MA, Sharpe A, Wherry EJ. Genetic absence of PD-1 promotes accumulation of terminally differentiated exhausted CD8+ T cells. J Exp Med. 2015;212(7):1125-37.

24. Porter DL, Hwang WT, Frey NV, Lacey SF, Shaw PA, Loren AW, et al. Chimeric antigen receptor $T$ cells persist and induce sustained remissions in relapsed refractory chronic lymphocytic leukemia. Sci Transl Med. 2015;7(303):303ra139.

25. Patsoukis N, Brown J, Petkova V, Liu F, Li L, Boussiotis VA. Selective effects of PD-1 on Akt and Ras pathways regulate molecular components of the cell cycle and inhibit T cell proliferation. Sci Signal. 2012;5(230):ra46.

26. Restifo NP. Big bang theory of stem-like T cells confirmed. Blood. 2014; 124(4):476-7.

27. Wherry EJ, Kurachi M. Molecular and cellular insights into T cell exhaustion. Nat Rev Immunol. 2015:15(8):486-99.

28. Xu Y, Zhang M, Ramos CA, Durett A, Liu E, Dakhova O, et al. Closely related T-memory stem cells correlate with in vivo expansion of CAR.CD19-T cells and are preserved by IL-7 and IL-15. Blood. 2014;123(24):3750-9.
29. Yang S, Ji Y, Gattinoni L, Zhang L, Yu Z, Restifo NP, et al. Modulating the differentiation status of ex vivo-cultured anti-tumor T cells using cytokine cocktails. Cancer Immunol Immunother. 2013;62(4):727-36.

30. Singh H, Figliola MJ, Dawson MJ, Huls H, Olivares S, Switzer K, et al. Reprogramming CD19-specific T cells with IL-21 signaling can improve adoptive immunotherapy of B-lineage malignancies. Cancer Res. 2011; 71(10):3516-27.

31. Long $A H$, Haso WM, Shern JF, Wanhainen KM, Murgai M, Ingaramo M, et al. 4-1BB costimulation ameliorates $T$ cell exhaustion induced by tonic signaling of chimeric antigen receptors. Nat Med. 2015;21(6):581-90.

32. Ouchi Y, Patil A, Tamura Y, Nishimasu H, Negishi A, Paul SK, et al. Generation of tumor antigen-specific murine CD8+ T cells with enhanced anti-tumor activity via highly efficient CRISPR/Cas9 genome editing. Int Immunol. 2018; 30(4):141-54.

33. Rupp LJ, Schumann K, Roybal KT, Gate RE, Ye CJ, Lim WA, et al. CRISPR/ Cas9-mediated PD-1 disruption enhances anti-tumor efficacy of human chimeric antigen receptor T cells. Sci Rep. 2017:7(1):737.

34. Liu X, Zhang Y, Cheng C, Cheng AW, Zhang X, Li N, et al. CRISPR-Cas9mediated multiplex gene editing in CAR-T cells. Cell Res. 2017;27(1):154-7.

35. Pranam Chatterjee NP, Gordon J. Freeman and Vassiliki A. Boussiotis. Distinct Roles Of PD-1 Itsm and ITIM In Regulating Interactions With SHP-2, ZAP-70 and Lck, and PD-1-Mediated Inhibitory Function. Blood. 2013; 122(21):191

36. Q Qiong Jia FY, Huang W, Zhang Y, Bao B, Li K, Wei F, Zhang C, Jia H. Low Levels of Sox2 are required for Melanoma Tumor-Repopulating Cell Dormancy. Theranostics. 2019:9(2):424-35.

37. Davenport AJ, Cross RS, Watson KA, Liao Y, Shi W, Prince HM, et al. Chimeric antigen receptor $T$ cells form nonclassical and potent immune synapses driving rapid cytotoxicity. Proc Natl Acad Sci U S A. 2018;115(9):E2068-E76.

38. Harris DT, Kranz DM. Adoptive T cell therapies: a comparison of $\mathrm{T}$ cell receptors and chimeric antigen receptors. Trends Pharmacol Sci. 2016; 37(3):220-30

39. Oren R, Hod-Marco M, Haus-Cohen M, Thomas S, Blat D, Duvshani N, et al. Functional comparison of engineered T cells carrying a native TCR versus TCR-like antibody-based chimeric antigen receptors indicates affinity/avidity thresholds. J Immunol. 2014;193(11):5733-43.

40. Simon S, Vignard V, Florenceau L, Dreno B, Khammari A, Lang F, et al. PD-1 expression conditions $T$ cell avidity within an antigen-specific repertoire. Oncoimmunology. 2016:5(1):e1104448.

\section{Publisher's Note}

Springer Nature remains neutral with regard to jurisdictional claims in published maps and institutional affiliations.

Ready to submit your research? Choose BMC and benefit from:

- fast, convenient online submission

- thorough peer review by experienced researchers in your field

- rapid publication on acceptance

- support for research data, including large and complex data types

- gold Open Access which fosters wider collaboration and increased citations

- maximum visibility for your research: over $100 \mathrm{M}$ website views per year

At $\mathrm{BMC}$, research is always in progress.

Learn more biomedcentral.com/submissions 